\title{
Diode Laser - A Novel Therapeutic Approach in the Treatment of Chronic Periodontitis in Type 2 Diabetes Mellitus Patients: A Prospective Randomized Controlled Clinical Trial
}

\author{
Sourav Chandra ${ }^{1}$, Pratibha Shashikumar ${ }^{2 *}$ \\ 'Department of Periodontology \& Implantology, Hazaribag College of Dental Sciences \& Hospital, Hazaribag, Jharkhand- \\ 825301, India \\ ${ }^{2}$ Department of Periodontology, JSS Dental College \& Hospital (Constituent College), Jagadguru Sri Shivarathreeshwara \\ University, Mysuru- 570015, Karnataka, India
}

\author{
*Correspondence to \\ Pratibha Shashikumar, MDS; \\ Department of Periodontology, \\ ISS Dental College \& Hospital \\ (Constituent College) \\ Jagadguru Sri Shivarathreeshwara \\ University, \\ ISS Medical Institutions Campus, \\ Sri Shivarathreeshwara Nagar, \\ Mysuru- 570015 \\ Karnataka, India \\ Tel: +9986544409 \\ Email: drpratibhavg@gmail.com
}

Published online 15 December 2018

\begin{abstract}
Introduction: Maturity-onset diabetes mellitus affecting the elderly population is marked by insulin resistance and decreased insulin production. The relationship between periodontitis and diabetes is bidirectional. Type 2 diabetic patients are more prone to chronic periodontitis (CP) and severe periodontitis affects the glycemic control in such patients. Recently, dental diode laser has become an effective tool in controlling CP. To date, very few studies have been conducted to check the efficacy of diode laser in control of periodontal destruction in type 2 diabetes mellitus (DM2) patients. Hence, the need of the study was to evaluate whether diode laser helps improvement of periodontal outcome and reduction in anaerobic bacteria in elderly diabetic patients with $\mathrm{CP}$.

Methods: Forty DM2 patients with CP were randomized into group A (control): scaling and root planing (SRP) only and group B (test): SRP followed by soft tissue dental diode laser (808 nm) application. Four patients ( 2 in each group) were lost during follow up. Clinical parameters, plaque samples and glycated hemoglobin levels were evaluated at both baseline and 90 days post-treatment.

Results: Improvement in clinical, microbiological and glycemic parameters were noted in the group that received SRP as well as SRP + LANAP (laser-assisted new attachment procedure). The reductions in clinical parameters were statistically significant after 3 months $(P<0.001)$. The microbial analysis of plaque samples for Aggregatibacter actinomycetemcomitans (Aa) and Porphyromonas gingivalis $(P g)$ decreased significantly after 3 months in group B than in group A. Glycated hemoglobin level (HbA1c) decreased significantly after 90 days in both the groups $(P<0.001)$ with more reduction in the SRP+LANAP group (6.49\%) in comparison to SRP alone (16.25\% vs. 9.76\%). However, on the intergroup comparison, the difference in $\mathrm{HbA} 1 \mathrm{c}$ reduction was nonsignificant.

Conclusion: Laser as an adjunct to SRP is an effective procedure for improving clinical and microbiological parameters in maturity onset diabetes mellitus patients with CP. Also, there was a better improvement in glycemic control in the test group compared to control group after 3 months. Hence, medically compromised patients like DM2 with CP with delayed wound healing can effectively be treated by laser as an adjunct to nonsurgical periodontal therapy for better results. Keywords: Chronic periodontitis; Diode laser; Diabetes mellitus; HbA1c; LANAP; Microbiology; Nonsurgical periodontal therapy.
\end{abstract}

\section{Introduction}

Chronic periodontitis (CP) is a multifactorial disease caused by various periodontopathogenic bacteria that results in the destruction of the tooth-supporting tissues i.e. periodontal tissue. ${ }^{1}$ Diabetes mellitus is a chronic metabolic disorder of the pancreas that results in marked hyperglycemia due to insulin resistance and decreased production of insulin by the pancreas. ${ }^{2,3}$ Non-insulin dependent diabetes mellitus (NIDDM) also known as type 2 diabetes mellitus (DM2) is more common in the elderly population. Periodontitis is considered a sixth complication in diabetic patients. The relationship between Periodontitis and NIDDM is bidirectional. NIDDM predisposes an individual to the risk of developing CP, and severe periodontitis affects glycemic control in diabetic patients. ${ }^{4}$ Few meta-analyses studies have confirmed that $\mathrm{HbAlc}$ reduction of around $0.4 \%$ can be anticipated following effective periodontal therapy. ${ }^{5}$ The primary etiological factor for the existence of periodontitis is pathogenic microorganisms within the

Please cite this article as follows: Chandra S, Shashikumar P. Diode laser - a novel therapeutic approach in the treatment of chronic periodontitis in type 2 diabetes mellitus patients: a prospective randomized controlled clinical trial. J Lasers Med Sci. 2019;10(1):56-63. doi:10.15171/jlms.2019.09. 
subgingival biofilm. Specific periodontopathogenic bacterial species and their virulence factors have been recognized as etiological agents and they affect the rate of progression of the disease. Hence, they act as indicators for progression of periodontal breakdown. ${ }^{6}$ Today about a dozen oral microorganisms are classified as periodontal pathogens. Foremost among these are gram-negative organisms including Aggregatibacter actinomycetemcomitans (Aa) and Porphyromonas gingivalis $(\mathrm{Pg}){ }^{7}$

The elimination of subgingival microorganism and regeneration of lost tissue is considered as the most important goal of periodontal therapy. Successful periodontal therapy is determined by control of destructive periodontal pathogens along with a shift in the microbial flora towards one that is typically present in health..$^{8-10}$ This elimination of the pathogenic subgingival microbiota can be achieved by nonsurgical periodontal therapy which is considered as the gold standard for a plaque as well as microbial elimination. ${ }^{10-12}$ However, previous studies have shown that nonsurgical periodontal therapy alone may fail to completely eliminate the pathogenic subgingival microbiota because of limited access to the instruments, as a result, this may lead to persistent periodontopathogens. ${ }^{10,13-15}$ These limitations of mechanical therapy have led to a shift to other adjunctive measures such as the use of antimicrobial therapy.

The spread of localized inflammation which is closely associated with the destruction of the supporting periodontal tissue is promoted by the microbial colonization, especially the gram-negative anaerobic bacteria in deep inaccessible areas such as furcation areas and root concavities. This justifies the need for the bacterial elimination from periodontal pockets. ${ }^{16}$ Mechanical methods such as scaling and root planing (SRP) are not sufficient for the complete bacterial elimination. ${ }^{17,18}$ Systemic antibiotics have been employed in cases which are nonresponsive to conventional periodontal treatments in spite of the known systemic side effects of antibiotics and the development of antibiotic resistance. ${ }^{1,19}$ Dental diode laser system has become an effective tool when used along with conventional periodontal therapy resulting in significant bacterial reduction which makes the adjunctive use of antibiotics almost unnecessary. ${ }^{20}$

Lasers have been used in periodontal therapy since long for subgingival curettage, gingivectomy, frenectomy, removal of granulation tissue, during flap surgery, osseous recontouring, implant maintenance and management of peri-implantitis.

The antimicrobial efficacy of diode laser has been proven in a number of studies. ${ }^{7}$ Due to its exceptional ease of use and affordability as well as action on various pigmented periodontal pathogens the diode laser has become an integral tool in the dental armamentarium. ${ }^{21}$ It is well absorbed by various chromophores present in diseased periodontal tissues such as melanin and hemoglobin. ${ }^{22}$
These evidence in the dental literature states diode laser is a useful adjunct to nonsurgical periodontal therapy in producing improved results. ${ }^{23}$

Although several studies have shown the efficacy of soft tissue diode laser therapy over SRP alone in the treatment of $\mathrm{CP}$, very few studies were done in NIDDM patients who are frequently affected by $\mathrm{CP}$ due to bidirectional relationship and to assess whether laser-assisted new attachment procedure (LANAP) has additional systemic beneficial effect on glycemic control, improvement in overall clinical outcome and the reduction in periodontal microbiology.

\section{Methods}

A total of 40 DM2 patients with CP were selected from the Department of Periodontology, JSS Dental College, and Hospital, Mysuru between April 2016 and September 2017.

\section{Data Collection}

\section{Inclusion Criteria}

- Patients between 30-60 years of age with confirmed diagnosis of DM2 and chronic generalized periodontitis with $\geq 20$ teeth remaining.

- The periodontal pocket depth of 4-7 $\mathrm{mm}$ with clinical attachment level (CAL) of $2 \mathrm{~mm}$ or greater and each quadrant having at least 3 teeth.

- Consenting patients who were cooperative and able to come for regular follow up.

\section{Exclusion Criteria}

- Pregnant/lactating women.

- Patients who were on antibiotic therapy in the previous six months.

- Patients who had undertaken any periodontal therapy in past 6 months.

- Smoking.

- Alcoholism.

\section{Sample Size}

By purposive sampling, 40 patients were selected who fulfilled the inclusion criteria. Four patients ( 2 in test and 2 in control) were lost during follow-up. After baseline examination, 36 patients were assigned randomly to test and control group of 18 patients each (Figure 1).

\section{Study Design}

This was a parallel design, randomized, single-blind, and controlled clinical trial of 3 months duration. The study was conducted to compare and evaluate Diode Laser therapy as an adjunct to SRP in NIDDM patients with CP.

- Group A (Control group): SRP followed by irrigation with normal saline.

- Group B (Test group): SRP followed by diode laser application (laser assisted new attachment procedure, LANAP) and irrigation with normal saline. 


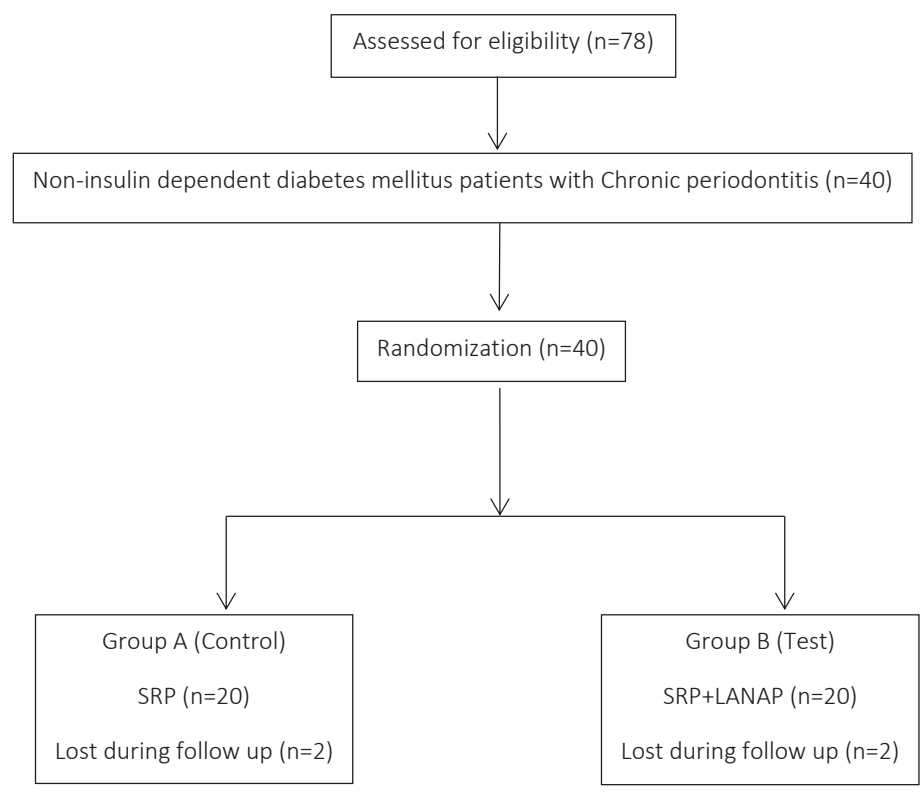

Figure 1. Consort Diagram of the Study.

\section{Randomization}

The randomization of 36 patients was done as follows. 36 type 2 diabetes and $\mathrm{CP}$ reported to the investigator of the study. The investigator who was blind to the study protocol then randomly assigned 36 patients into test and control group by sequentially numbered sealed opaque envelopes. The operator then according to the treatment assigned in the sealed envelope treated the patients either by SRP alone or SRP+LANAP and then recalled the patients after 3 months for follow-up.

All the patients who had participated in the study fulfilling the inclusion criteria had to fill an informed consent prior to the study.

\section{Study Protocol}

- In the first visit oral hygiene instructions were given.

- Patients were then recalled after 7 days for baseline blood investigation (HbAlc), a collection of subgingival plaque samples and measurements of clinical parameters followed by nonsurgical periodontal therapy in control group and SRP followed by LANAP in the test group.

- Subgingival plaque samples were sent for microbiological analysis.

- Laser application was done with the help of an active diode laser (Mikro Sunny $808 \mathrm{~nm}$ diode laser). A wavelength $808 \mathrm{~nm}$ and a power setting of $1.5 \mathrm{~W}-1.8$ $\mathrm{W}$ were used in continuous, contact mode with a thin flexible fiber-optic cable $(320 \mathrm{~nm})$. The fiber optic cable was introduced into the periodontal pocket with the laser beam directed towards the soft tissue of the pocket wall and moved in an apico-coronal direction, with a sweeping motion. The depth of the periodontal pocket in millimeters corresponds to the exposure time in seconds

- Patients were again recalled at 3 months for assessment of clinical, microbiological and $\mathrm{HbAlc}$ level posttreatment.

- Patients were monitored periodically for oral hygiene maintenance and recalled for further periodontal therapy as needed.

Clinical Parameters Assessed

Baseline and 3 months assessment of the following full mouth clinical parameters:

- $\quad$ Plaque index (PI) (Silness and Loe,1964) $)^{24}$

- $\quad$ Gingival index (GI) (Loe and Silness, 1967) ${ }^{24}$

- CAL - using a UNC-15 probe from a fixed reference point on the crown to the base of the pocket.

- Probing depth (PD) - using a UNC-15 probe taken from the margin of the gingiva to the base of the pocket.

Microbiological Analysis

The collection of plaque sample was done in the Department of Periodontology, JSS Dental College, and Hospital, Mysuru. Collection of subgingival plaque samples was done by the same operator to standardize the sampling procedure. Before sampling, the adjacent teeth were isolated with cotton rolls. To standardize site selection and adequate sample volume, plaque sample was collected from all the quadrants and pooled in reduced transport fluid (RTF) medium for microbiological analysis. Plaque samples contaminated with blood and saliva were discarded. The samples were then immediately transferred for microbiological culturing of $\mathrm{Aa}$ and $\mathrm{Pg}$ which were then separately vortexed and inoculated in anaerobic jar according to the requirement for culturing 
and quantification of anaerobic bacteria.

\section{Statistical Analysis}

The values obtained from the clinical, microbiological and hematological data were subjected to following statistical analysis:

- Descriptive statistics - mean and standard deviation.

- Paired samples "t-test" for within group comparison.

- Independent-samples $t$ test for comparison between 2 groups.

The data obtained were processed using statistical software (SPSS 22 for Windows).

\section{Results}

The study outline is explained in Figure 1. The demographic data of the patients at baseline are illustrated in Table 1.

Clinical Parameters

There was a statistically significant improvement

Table 1. Demographic Data of the Test (SRP+LANAP) and Control (SRP) Group at Baseline

\begin{tabular}{lll}
\hline & SRP $(\mathbf{n}=\mathbf{1 8})$ & SRP+LANAP $(\mathbf{n}=\mathbf{1 8})$ \\
\hline Age & $50.6(7.25)$ & $48.05(6.05)$ \\
Gender & & \\
$\quad$ Male & 9 & 9 \\
$\quad$ Female & 9 & 9 \\
BMI & $23.9 \pm 0.6$ & $23.7 \pm 0.7$ \\
HbA1c mean $(\%)$ & $7.994 \pm 1.2744$ & $8.122 \pm 1.2744$ \\
PI & $2.3194 \pm 0.26352$ & $2.45 \pm 0.25$ \\
Gl & $2.38667 \pm 0.369610$ & $2.19 \pm 0.2234$ \\
PD $(\mathrm{mm})$ & $3.5911 \pm 0.33582$ & $3.6406 \pm 0.3902$ \\
CAL $(\mathrm{mm})$ & $8.7361 \pm 0.7682$ & $8.6739 \pm 0.7046$ \\
\hline
\end{tabular}

Abbreviations: $\mathrm{Pl}$, plaque index; Gl: gingival index: PD: probing depth; CAL: clinical attachment level; SRP: scaling and root planning; LANAP: Laser-assisted new attachment procedure. in clinical parameters from baseline to 3 months postoperatively $(P<0.001)$ (Table 2$)$. The results are displayed in boxplots diagrams in Figure 2.

\section{$\operatorname{HbAlc}(\%)$}

The results of $\mathrm{HbAlc}$ values are depicted in Figure 3. The values of $\mathrm{HbAlc}$ in the test site decreased from $8.122 \pm 1.26$ at baseline to $6.833 \pm 0.651$ at 3 months and in the control, site decreased from $7.994 \pm 1.27$ at baseline to $7.217 \pm 0.793$ at 3 months. There was $6.49 \%$ more reduction in HbAlc levels in the SRP+LANAP group compared to SRP alone (16.25\% vs. 9.76\%) but on intergroup comparison the difference in HbAlc reduction was nonsignificant. The changes in $\mathrm{HbAlc}(\%)$ are shown in Table 3.

\section{Microbiological Analysis}

The collection of subgingival plaque samples for the culturing of anaerobic bacteria was done at baseline and 3 months postoperatively. The results in $\mathrm{CFU} / \mathrm{mL}$ of $\mathrm{Aa}$ and $P g$ are shown in (Figure 4).

\section{Colony Count of $A a(\mathrm{CFU} / \mathrm{mL})$}

The colony count of $A a$ in control group decreased from $104.44 \pm 20.643$ to $56.11 \pm 19.363$ and from $112.78 \pm$ 19.33 to $15.00 \pm 8.22$ in the test group. The comparison between the treatment groups revealed $46.27 \%$ reduction of $A a$ in control group and $86.69 \%$ reduction of $A a$ in test showing that test group had $40.4 \%$ more significant reduction in Aa than control. Thus, on intergroup comparison statistical significant reduction was observed in colony count of $A a$ in test group than in control after 3 months (Table 4, Figure 4)

Colony Count of $P g(\mathrm{CFU} / \mathrm{mL})$

The colony count of $P g$ in CFU/ml decreased from 102.50 \pm 33.61 at the baseline to $14.72 \pm 12.18$ at 3 months in the

Table 2. Clinical Parameters Assessment at Day Zero and 90 Days in the Test and Control Groups ${ }^{a}$

\begin{tabular}{|c|c|c|c|c|}
\hline Clinical Parameter & Evaluation Point & Group A (SRP) & Group B (SRP+LANAP) & $P$ Value \\
\hline \multirow{3}{*}{$\mathrm{PI}$} & Day 0 & $2.3194 \pm 0.26352$ & $2.45 \pm 0.25$ & \multirow{3}{*}{$0.003^{b}$} \\
\hline & 90 days & $1.56917 \pm 0.323484$ & $1.26 \pm 0.22$ & \\
\hline & $P$ value & $0.000^{\mathrm{b}}$ & $0.000^{\mathrm{b}}$ & \\
\hline \multirow{3}{*}{ GI } & Day 0 & $2.38667 \pm 0.369610$ & $2.19 \pm 0.2234$ & \multirow{3}{*}{$0.000^{\mathrm{b}}$} \\
\hline & 90 days & $1.5556 \pm 0.32333$ & $1.04 \pm 0.2275$ & \\
\hline & $P$ value & $0.000^{b}$ & $0.000^{\mathrm{b}}$ & \\
\hline \multirow{3}{*}{$\mathrm{PD}(\mathrm{mm})$} & Day 0 & $3.5911 \pm 0.33582$ & $3.6406 \pm 0.3902$ & \multirow{3}{*}{$0.000^{b}$} \\
\hline & 90 days & $2.6339 \pm 0.39313$ & $1.8050 \pm 0.3278$ & \\
\hline & $P$ value & $0.000^{b}$ & $0.000^{\mathrm{b}}$ & \\
\hline \multirow{3}{*}{$\mathrm{CAL}(\mathrm{mm})$} & Day 0 & $8.7361 \pm 0.7682$ & $8.6739 \pm 0.7046$ & \multirow{3}{*}{$0.000^{\mathrm{b}}$} \\
\hline & 90 days & $7.5011 \pm 0.5242$ & $6.6511 \pm 0.5315$ & \\
\hline & $P$ value & $0.000^{\mathrm{b}}$ & $0.000^{\mathrm{b}}$ & \\
\hline
\end{tabular}

Abbreviations: PI, plaque index; GI, gingival index; PD, probing depth; CAL, clinical attachment level; SRP, scaling and root planning; LANAP, Laser-assisted new attachment procedure.

${ }^{a}$ Data are shown as Mean \pm SD.

${ }^{b}$ Statistically significant. 

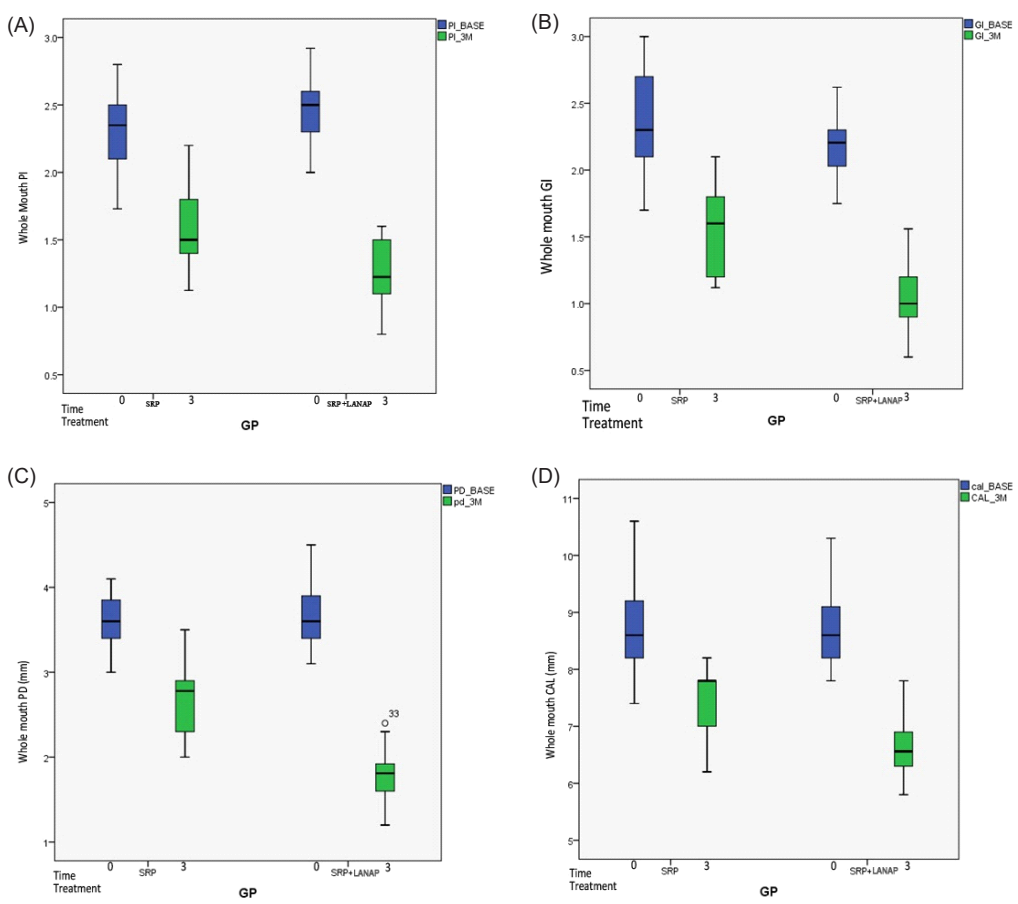

Figure 2. A) Plaque Index B) Gingival Index C) Probing Depth D) Clinical Attachment Level Assessed at Day Zero and 90 Days Posttreatment.

test group and from $101.39 \pm 33.64$ at the baseline to 50.00 \pm 21.351 at three months in control. The comparison between the treatment groups revealed $85.15 \%$ reduction of $P g$ in test group and $50.64 \%$ reduction of $P g$ in control group showing that the test group had 35\% more significant reduction of $\mathrm{Pg}$ than in control.

Thus, on intergroup comparison statistical significant reduction was observed in colony count of $\mathrm{Pg}$ in test group than in control after 3 months (Table 4, Figure 4).

\section{Discussion}

The current study shows a better reduction of HbAlc levels, in laser treated group (16.25\%) than in SRP treated group (9.76\%) after 3 months but this reduction was not statistically significant on the intergroup comparison from baseline to 3 months. The values of HbAlc at 3 months

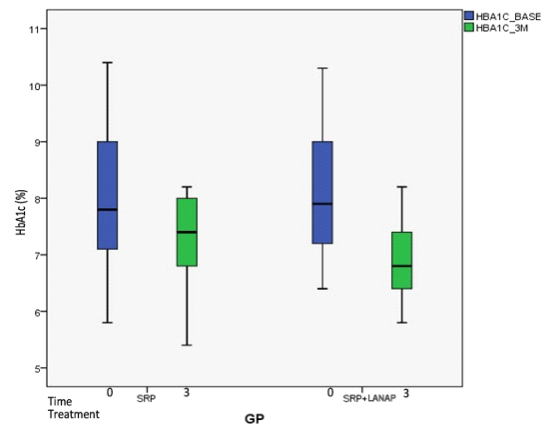

Figure 3. Mean $\mathrm{HbA1c}(\%)$ Level at Day 0 and 90 Days in SRP Group and SRP+LANAP Group. postoperatively decreased from $8.12 \%$ to $6.8 \%$ in the test group (SRP+LANAP) and $7.9 \%$ to $7.2 \%$ in control group (SRP). In the present study, the lowering of HbAlc levels after nonsurgical periodontal therapy was in accordance with previously reported studies. ${ }^{25-29}$

Previous studies had linked obesity and smoking as
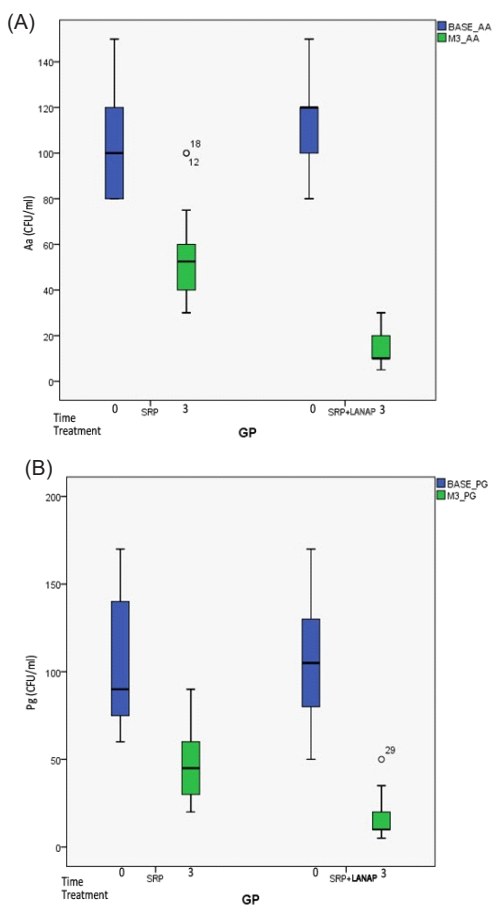

Figure 4. Mean Reduction in $\mathrm{CFU} / \mathrm{mL}$ of Aggregatibacter actinomycetemcomitans ( $\mathrm{Aa}$ ) and Porphyromonas gingivalis (Pg) From Baseline to 3 Months. 
Table 3. Glycemic Parameters in Group A and Group Ba

\begin{tabular}{lllll}
\hline Clinical Parameter & Evaluation Point & Group A (SRP) & Group B (SRP+LANAP) & P Value \\
\hline & Day 0 & $7.994 \pm 1.2744$ & $8.122 \pm 1.2744$ & 0.121 \\
HbA1c (\%) & 90 days & $7.2178 \pm 0.79353$ & $6.8333 \pm .65169$ & $0.000^{\mathrm{b}}$ \\
& $P$ value & $0.000^{\mathrm{b}}$ & & \\
\hline
\end{tabular}

Abbreviation: HbA1c: Glycated hemoglobin level.

a Data are shown as Mean \pm SD.

${ }^{b}$ Statistically significant.

Table 4. Microbiological Parameters in CFU/mL at Day Zero and 90 Days in the Test and Control Groups ${ }^{a}$

\begin{tabular}{|c|c|c|c|c|}
\hline Clinical Parameter & Evaluation Point & Group A (SRP) & Group B (SRP+LANAP) & $P$ Value \\
\hline \multirow{3}{*}{$\mathrm{Aa}(\mathrm{CFU} / \mathrm{mL})$} & Day 0 & $104.44 \pm 20.643$ & $112.78 \pm 19.34$ & \multirow{3}{*}{$0.000^{\mathrm{b}}$} \\
\hline & 90 days & $56.11 \pm 19.369$ & $15.00 \pm 8.225$ & \\
\hline & $P$ value & $0.000^{\mathrm{b}}$ & $0.000^{\mathrm{b}}$ & \\
\hline \multirow{3}{*}{$\operatorname{Pg}(\mathrm{CFU} / \mathrm{mL})$} & Day 0 & $101.39 \pm 33.642$ & $102.50 \pm 33.618$ & \multirow{3}{*}{$0.000^{\mathrm{b}}$} \\
\hline & 90 days & $50.00 \pm 21.35$ & $14.72 \pm 12.18$ & \\
\hline & $P$ value & $0.000^{\mathrm{b}}$ & $0.000^{\mathrm{b}}$ & \\
\hline
\end{tabular}

Abbreviations: Aa, Aggregatibacter actinomycetemcomitans; Pg, Porphyromonas gingivalis.

a Data are shown as Mean \pm SD.

${ }^{\text {b }}$ Statistically significant.

confounding factors to diabetes mellitus and $\mathrm{HbA1c}$ control in patients with $\mathrm{CP} .{ }^{27}$ In the present study patients had confirmed diagnosis of DM2, with a mean BMI $<24$ $\mathrm{kg} / \mathrm{m}^{2}$, and were nonsmokers, which positively helped in assessing the bidirectional relationship of DM2 and CP. The outcome of the current study was similar with those of two recent investigations that examined the effect of PDT alone and in combination with SRP in patients receiving initial and supportive periodontal therapy. Because PDT had no reported systemic effect, there was no reason to assume that it would improve HbA1c levels. ${ }^{30,31}$

This is in contradiction to a recent study by Koçak and Sağlam which showed SRP+ Diode laser group showed statistically significant improvement in glycemic control (HbAlc) than in SRP group in patients with DM2 and $\mathrm{CP}^{32}$

The present study showed improvement in all clinical parameters (PI, GI, PD, CAL) from baseline to 3 months in SRP and SRP+LANAP group which was statistically significant.

The value of plaque index reduced from 2.31 at baseline to 1.56 at 3 months in control and from 2.45 to 1.26 in the test group. This observation is in accordance with a study done by Berakdar et al. ${ }^{33}$

The value of GI score reduced from 2.23 at baseline to 1.55 at 3 months after therapy in control and from 2.19 to 1.04 in the test group. This is in accordance with a study by Fallah where after 6 weeks there is compelling evidence of improvement in gingival. ${ }^{34}$

The mean reduction of PD and CAL from baseline to 3 months in the present study were similar with those obtained by other studies. ${ }^{7,35-38}$ A study was done by Obradovic et al where laser as an adjunct to SRP showed significant improvement in gingival inflammation compared to SRP alone in NIDDM patients. ${ }^{39}$ Another histologic study by Obradovic et al, showed a faster healing response when SRP was combined with DL in NIDDM patients. ${ }^{40}$

In a study by Yukna et al laser as an adjunct to SRP resulted in significant reduction of $\mathrm{PD}$ with a gain in CAL. ${ }^{41}$ This reduction in PD can be explained due to better pocket epithelial lining removal by soft tissue diode laser leading to connective tissue attachment directly to root surface favoring regeneration as reported by Kreisler et al. ${ }^{36} \mathrm{~A}$ similar study conducted on animals by Romanos et al. ${ }^{42}$ showed better removal of pocket epithelial lining in DL+SRP group compared to conventional hand instruments. Hence, the abovementioned studies suggest that a better response in clinical parameters can be achieved when diode laser is used as an adjunct to conventional SRP.

The present study showed a significant reduction in colony count $(\mathrm{CFU} / \mathrm{mL})$ of $A a$ and $P g$ from base line to 3 months follow-up in both the groups. The colony count of $A a$ in control group decreased from $104.44 \pm 20.643$ to $56.11 \pm 19.363$ and from $112.78 \pm 19.33$ to $15.00 \pm 8.22$ in the test group. The microbial count of $A a$ revealed $46.27 \%$ reduction in control group and $86.69 \%$ reduction in test showing that test group had $40.4 \%$ more reduction in $A a$ than control. Also, the colony count of $P g(\mathrm{CFU} / \mathrm{mL})$ decreased from $102.50 \pm 33.618$ at the baseline to 14.72 \pm 12.184 at 3 months in the test group and from 101.39 \pm 33.642 at the baseline to $50.00 \pm 21.351$ at 3 months in control. The mean percentage decrease of $P g$ was $50.64 \%$ in control group and $85.15 \%$ in test group showing that the test group had 35\% more reduction of $\mathrm{Pg}$ than in control. This is because of the fact that diode laser is effective against many putative periodontal pathogens including 
$A a$ and $P g$ and its ability to reach inaccessible periodontal sites which had been proved in previous studies. ${ }^{43}$

Thus, the present study shows that diode laser application is effective in reducing inflammation due to the antimicrobial property of laser. A classic study by Pick and Colvard et al in 1998 on the treatment of periodontal pockets using $810 \mathrm{~nm}$ diode lasers showed immediate structural damage of gram-negative bacteria and a marked reduction of periodontopathogens namely $\mathrm{Aa}$ and $\mathrm{Pa}{ }^{7,44}$ Diode laser is effective not only in the elimination of bacteria from the periodontal pocket but also the complete removal of bacterial toxins from root cementum. ${ }^{45}$ Another study by Lin et al showed marked reduction of $A a$ and prevent further recolonization for up to 28 days using diode lasers. ${ }^{46}$

\section{Conclusion}

The present study showed statistically significant improvement in clinical and microbiological parameters in the test than in control group from baseline to 3 months. Thus we can conclude that the use of diode laser therapy after SRP is more effective than SRP alone in the overall improvement of clinical and microbiological parameters. Also, the adjunctive use of soft tissue diode laser resulted in better improvement in HbAlc in NIDDM patients than SRP alone after 3 months. The percentage decrease in HbAlc was (16.25\%) in test versus (9.76 \%) in control but the difference between the groups was not statistically significant. This suggests the need for further long-term randomized controlled clinical trials with larger sample size before generalizing that diode laser therapy results in improved glycemic control in maturity onset diabetes mellitus patients with CP.

\section{Ethical Considerations}

The study was conducted after obtaining ethical clearance form ethical review committee JSS Dental College and Hospital, Mysuru. The study was registered in clinical trials registry-India with (identifier: CTRI/2017/11/010348).

\section{Conflict of Interests}

The authors declare no conflict of interest.

\section{Funding}

The study was funded by JSS university research grant with registration number REG/DIR(R)/URG/ 54/2011$12 / 10888 / 1$.

\footnotetext{
Acknowledgments

We sincerely acknowledge JSS Academy of Higher Education and Research for research grants support and respected Head of the department Dr. Sheela Kumar for her constant support and invaluable insights during this dissertation. Also, I would like to thank Dr. Lancy D Souza statistician and Mr. Patel who helped me in my dissertation work.
}

\section{References}

1. Darveau RP, Tanner A, Page RC. The microbial challenge in periodontitis. J Periodontol 2000.1997;14:12-32.

2. Barr EL, Zimmet PZ, Welborn TA, et al. Risk of cardiovascular and all-cause mortality in individuals with diabetes mellitus, impaired fasting glucose, and impaired glucose tolerance: The Australian Diabetes, Obesity, and Lifestyle Study (AusDiab). Circulation. 2007;116:151-1517. doi:10.1161/CIRCULATIONAHA.106.685628

3. Löe H. Periodontal disease. The sixth complication of diabetes mellitus. Diabetes Care. 1993;16:329-334.

4. Preshaw PM, Alba AL, Herrera D, et al. Periodontitis and diabetes: A two-way relationship. Diabetologia. 2012;55:2131. doi:10.1007/s00125-011-2342-y

5. Teeuw WJ, Gerdes VEA, Loos BG. Effect of periodontal treatment on glycemic control of diabetic patients: a systematic review and meta-analysis. Diabetes Care. 2010;33:421-427. doi:10.2337/dc09-1378

6. Wolf HF, Hassel TM. Colour Atlas of Dental Hygiene: Periodontology. Theme; 2006.

7. Moritz A, Schoop U, Goharkhay K, Schauer P. Treatment of periodontal pockets with a diode laser. Lasers Surg Med. 1998;22:302-311.

8. Mousquès T, Listgarten MA, Phillips RW. Effect of scaling and root planing on the composition of the human subgingival microbial flora. J Periodontal Res. 1980;15:14451.

9. Hinrichs JE, Wolff LF, Pihlstrom B, Schaffer EM, Liljemark WF, Bandt CL. Effects of scaling and root planing on subgingival microbial proportions standardized in terms of their naturally occurring distribution. J Periodontol. 1985;56:187-94. doi:10.1902/jop.1985.56.4.187

10. Yilmaz. Effect of gallium arsenide diode laser on human periodontal disease: a microbiological and clinical study. Lasers Surg Med. 2002;30(1):60-6.

11. Garrett JS. Effects of non-surgical therapy on periodontitis in humans: a review. J Clin Periodontol. 1983;10:515-23.

12. Kaldahl WB, Kalkwarf KL, Patil KD. A review oflongitudinal studies that compared periodontal therapies. J Periodontol. 1993;64:243-253. doi:10.1902/jop.1993.64.4.243

13. Buchanan SA, Robertson PB.. Calculus removal by scaling/ root planing with and without surgical access. J Periodontol 1987;58(3):159-163. doi:10.1902/jop.1987.58.3.159

14. Matia JI, Bissada NF, Maybury JE, Richette P. Efficiency of scaling of molar furcation area with and without surgical access. Int J Periodontics Restorative Dent. 1986;6:25-35.

15. Adriaens PA, Edwards CA, De Boever JA, Loesche WJ. Ultrastructural observation on bacterial invasion in cementum and radicular dentin of periodontally diseased human teeth. J Periodontol. 1988;59:493-503. doi:10.1902/ jop.1988.59.8.493

16. Loesche WJ. The antimicrobial treatment of periodontal disease: Changing the treatment paradigm. Crit Rev Oral Biol Med. 1999;10(3):245-275.

17. Herrera D, Sanz M, Jepsen S, Needleman I, Roldan S. A systematic review on the effect of systemic antimicrobials as an adjunct to scaling and root planing in periodontitis patients. J Clin Periodontol. 2002;29(Suppl 3):136-59.

18. Haffajee AD, Cugini MA, Dibart S, Smith C, Kent RL, Socransky SS. Clinical and microbiological features of subjects with adult periodontitis who responded 
poorly to scaling and root planing. J Clin Periodontol. 1997;24(10):767-76.

19. Lopez NJ, Gamonal JA, Martinez B. Repeated metronidazole and amoxicillin treatment of periodontitis. A followup study. J Periodontol. 2000;71(1):79-89. doi:10.1902/ jop.2000.71.1.79

20. Löe H, Theilade E, Jensen SB. Experimental gingivitis in man. J Periodontol. 1965;36:177-187. doi:10.1902/ jop.1965.36.3.177

21. Dortbudak O, Haas R, Bernhart T, Mailath-Pokorny G. Lethal photosensitization for decontamination of implant surfaces in the treatment of peri-implantitis. Clin Oral Implants Res. 2001;12(2):104-108.

22. Coleton S. Lasers in surgical procedures and oral medicine. Dent Clin North Am. 2004;48:937-62. doi:10.1016/j. cden.2004.05.008

23. Lang NP, Brägger U. Periodontal diagnosis in the 1990s. $J$ Clin Periodontol. 1991;18:370-379.

24. Wolf HF, Rateitschak K. Periodontology. Vol 1. Thieme: 2005

25. Iwamoto Y, Nishimura F, Nakagawa M, et al. The effect of antimicrobial periodontal treatment on circulating tumor necrosis factor-alpha and glycated hemoglobin level in patients with type 2 diabetes. J Periodontol. 2001;72:774778. doi:10.1902/jop.2001.72.6.774

26. Kiran M, Arpak N, Unsal E, Erdogan MF. The effect of improved periodontal health on metabolic control in type 2 diabetes mellitus. J Clin Periodontol. 2005;32:266-272. doi:10.1111/j.1600-051X.2005.00658.x

27. Koromantzos PA, Makrilakis $\mathrm{K}$, Dereka $\mathrm{X}$, et al. A randomized, controlled trial on the effect of non-surgical periodontal therapy in patients with type 2 diabetes. Part I effect on periodontal status and glycaemic control. $J$ Clin Periodontol. 2011;38:142-147. doi:10.1111/j.1600051X.2010.01652.x

28. Navarro-Sanchez AB, Faria-Almeida R, BasconesMartinez. Effect of non-surgical periodontal therapy on clinical and immunological response and glycaemic control in type 2 diabetic patients with moderate periodontitis. J Clin Periodontol. 2007;34:835-843. doi:10.1111/j.1600051X.2007.01127.x

29. Borgnakke WS, Chapple IL, Genco RJ, et al. The multicenter randomized controlled trial (RCT) published by the journal of the American Medical Association (JAMA) on the effect of periodontal therapy on glycated hemoglobin (HbAlc) has fundamental problems. J Evid Based Dent Pract. 2014;14:127-132. doi:10.1016/j.jebdp.2014.04.017

30. Christodoulides N, Nikolidakis D, Chondros P, et al. Photodynamic therapy as an adjunct to non-surgical periodontal treatment: A randomized, controlled clinical trial. J Periodontol. 2008;79:1638-1644. doi:10.1902/ jop.2008.070652

31. Chondros P, Nikolidakis D, Christodoulides N, Rössler R, Gutknecht N, Sculean A. Photodynamic therapy as an adjunct to non-surgical periodontal treatment in patients on periodontal maintenance: A randomized controlled clinical trial. Lasers Med Sci. 2009;24:681-688. doi:10.1007/ s10103-008-0565-Z

32. Koçak1 E, Sağlam M. Nonsurgical periodontal therapy with/without diode laser modulates metabolic control of type 2 diabetics with periodontitis: a randomized clinical trial. Lasers Med Sci. 2016;31(2):343-53. doi:10.1007/ s10103-016-1868-0

33. Berakdar M, Callaway A, Eddin MF, Ross A, Willershausen B. Comparison between scaling-root-planing (SRP) and SRP/photodynamic therapy: a six-month study. Head Face Med. 2012;8:12. doi:10.1186/1746-160X-8-12

34. Fallah A. Effects of 980 diode laser treatments combined with scaling and root planing on periodontal pockets in chronic periodontitis patients. Lasers Dent. 2010;14:1-11.

35. Dukic W, Bago I, Aurer A, Roguljic M. Clinical effectiveness of diode laser therapy as an adjunct to nonsurgical periodontal treatment: a randomized clinical study. J Periodontol. 2013;84:1111-1117. doi:10.1902/ jop.2012.110708

36. Kreisler M, Al Haj H, d'Hoedt B. Clinical efficacy of semiconductor laser application as an adjunct to conventional scaling and root planing. Lasers Surg Med. 2005;37:350-355. doi:10.1002/lsm.20252

37. Qadri T, Miranda L, Tuner J, Gustafsson A. The shortterm effects of low-level lasers as adjunct therapy in the treatment of periodontal inflammation. J Clin Periodontol. 2005;32:714-719. doi:10.1111/j.1600-051X.2005.00749.x

38. Sağlam M, Kantarcı A, Dündar N, Hakkı SS. Clinical and biochemical effects of diode laser as an adjunct to nonsurgical treatment of chronic periodontitis: a randomized, controlled clinical trial. Lasers Med Sci. 2014;29:37-46. doi:10.1007/s10103-012-1230-0

39. Obradovic R, Kesic L, Mihailovic D, et al. Low-level lasers as an adjunct in periodontal therapy in patients with diabetes mellitus. Diabetes Technol Ther. 2012;14:799-803. doi:10.1089/dia.2012.0027

40. Obradovic R, Kesic L, Mihailovic D, Antic S, Jovanovic G et al A histological evaluation of a low-level laser therapy as an adjunct to periodontal therapy in patients with diabetes mellitus. Lasers Med Sci. 2013;28:19-24. doi:10.1007/ s10103-012-1058-7

41. Yukna RA, Carr RL, Evans GH. Histologic evaluation of a Nd: YAG laser-assisted new attachment procedure in humans. Int J Periodontics Restorative Dent. 2007;27:577587.

42. Romanos GE, Henze M, Banihashemi S, et al Removal of epithelium in periodontal pockets following diode $(980 \mathrm{~nm})$ laser application in the animal model: an in vitro study. Photomed Laser Surg. 2004;22:177-183. doi:10.1089/1549541041438597

43. Schwarz F, Sculean A, Berakdar M, Georg T, Reich E, Becker J. Periodontal treatment with an Er: YAG laser or scaling and root planing. A 2-year follow-up split-mouth study. J Periodontol. 2003;74(5):590-596. doi:10.1902/ jop.2003.74.5.590

44. Moritz A, Gutknecht N, Doertbudak O, et al. Bacterial reduction in periodontal pockets through irradiation with a diode laser: A pilot study. J Clin Laser Med Surg. 1997;15:33-7. doi:10.1089/clm.1997.15.33

45. Pick RM, Colvard MD. Current status of lasers in soft tissue dental surgery. J Periodontol. 1993; Jul;64(7):589-602. doi:10.1902/jop.1993.64.7.589

46. Lin PP, Rosen S, Beck FM, Matsue M, Horton JE. A comparative effect of the Nd: YAG Laser with root planing on subgingival anaerobes in periodontal pockets. J Dent Res. 1992;71:299. doi:10.1902/jop.1999.70.11.1276 